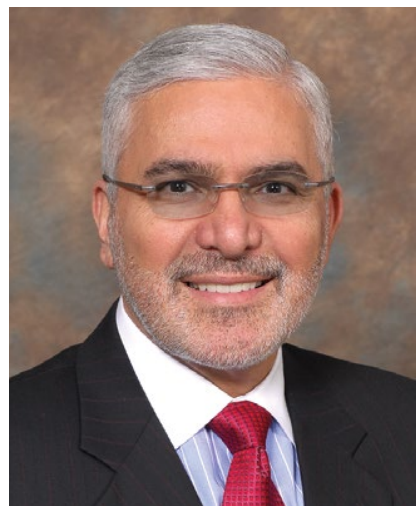

Henry A. Nasrallah, MD Editor-in-Chief doi: $10.12788 / \mathrm{cp} .0210$

\section{Psychiatric patients who} are unable to recognize their illness face many serious and damaging consequences

\title{
Is anosognosia a delusion, a negative symptom, or a cognitive deficit?
}

\section{Anosognosia is the lack of awareness} of a disabling physical or mental illness. The term was coined by Joseph Babinski in 1914 following his observations that patients with left-side paralysis due to right hemisphere stroke do not recognize their hemiplegia and strongly deny that there is anything physically wrong with their body, or that they need treatment or rehabilitation.

Psychiatrists have long observed anosognosia in patients with acute psychoses such as schizophrenia or mania who vehemently deny that there is anything wrong with them, despite experiencing hallucinations, delusions, and/or bizarre behavior. They adamantly refuse medical care and often have to be involuntarily hospitalized to receive urgently needed medications they don't believe they need.

So is anosognosia in schizophrenia a fixed false belief (delusion), a negative symptom, or a cognitive deficit? Arguments can be made for any of those 3 options, but the evidence suggests that anosognosia is a disorder of consciousness, a "metacognitive" deficit, or, as I referred to it in a previous publication, the loss of self-proprioception. ${ }^{1}$

\section{Anosognosia in neurologic brain disorders}

Although right hemispheric stroke is the most common disease state associated with anosognosia, ${ }^{2}$ other neurologic disorders can be associated with anosognosia, including Anton's syndrome of cortical blindness, ${ }^{3}$ traumatic brain injury, ${ }^{4}$ Wernicke's aphasia, ${ }^{5}$ mild cognitive impairment, ${ }^{6}$ and Alzheimer's disease. ${ }^{7}$ In addition to anosognosia, those disorders can be accompanied by indifference to the deficit, which is referred to as "anosodiaphoria."

The neuroanatomy of anosognosia generally implicates right hemisphere deficits, especially the frontal cortex, the right parietal lobe, the temporoparietal cortex, and the thalamus. It can be conceptualized as a disturbance of "body schema" because all motor and sensory functions of the body have a "representation" in brain structure.

\section{Anosognosia in psychiatric brain disorders}

Although schizophrenia is most frequently associated with anosognosia, other psychiatric disorders also exhibit this absence of insight. They include delusional disorder, ${ }^{8}$ bipolar disorder, ${ }^{9}$ intellectual disability, ${ }^{10}$ and personality disorders. ${ }^{11}$ In all those psychiatric disorders, there is a lack of self-reflection (metacognition). At the neuroanatomical 
level, most studies have focused on schizophrenia, and abnormalities have been described in the frontal and parietal regions. Significant pathology in the inferior parietal lobe has been identified in schizophrenia. ${ }^{12}$ However, the right insula, which is connected to multiple neural circuits, ${ }^{13}$ appears to be intimately associated with anosognosia when impaired. The insula also regulates interoception and a "sense of self." ${ }^{\prime 14}$ The loss of cortical gray matter in schizophrenia is most pronounced in the insula bilaterally. Another neurologic mechanism associated with anosognosia in schizophrenia is the default mode network (DMN). The $\mathrm{DMN}$, which usually is overactive at rest and is deactivated during a focused activity, is involved in both insight and social cognition. ${ }^{15}$

\section{Measurement of anosognosia}

Several rating scales are used to measure the severity of anosognosia and the loss of insight. They include:

- The Insight and Treatment Attitude Questionnaire $^{16}$

- The Scale to Assess Unawareness of Mental Disorder ${ }^{17}$

- The Beck Cognitive Insight Scale, ${ }^{18}$ the only self-administered scale that measures a patient's ability to evaluate their psychiatric beliefs and possibly modify them

- The Positive and Negative Syndrome Scale, ${ }^{19}$ which is the gold standard for measuring the overall severity of schizophrenia, has only 1 item related to insight within the 16-item General Subscale (G12: Lack of judgement and insight).

\section{Consequences of anosognosia}

Patients with anosognosia neglect themselves both mentally and physically and fail to seek or accept medical attention. Thus, schizophrenia is associated with many serious and damaging consequences due to the lack of self-monitoring or appraising their health needs. The Table (page 8 ) summarizes the multiple consequences of anosognosia.

\section{Is anosognosia treatable or irreversible?}

Schizophrenia is well established to be a heterogeneous syndrome with hundreds of biotypes that share a similar phenotype of positive, negative, cognitive, mood, and neuromotor symptoms of variable severities. ${ }^{20}$ This includes anosognosia, which has been reported in $57 \%$ to $98 \%$ of patients in various studies. ${ }^{21,22}$

So what happens to anosognosia with antipsychotic therapy? In the first study that used a long-acting injectable (LAI) second-generation antipsychotic (SGA) in first-episode psychosis to ensure full adherence, Emsley et $\mathrm{al}^{23}$ reported a $64 \%$ remission rate after 2 years of treatment, and observed that many patients regained their insight after several months of uninterrupted antipsychotic pharmacotherapy. This suggests that avoiding psychotic relapse with uninterrupted antipsychotic therapy with LAIs may help restore insight. I have personally witnessed reversal of anosognosia in patients with first-episode schizophrenia whom I treated with LAI SGAs continuously for several years; these patients not only regained insight into their illness but were able to return to college or to work.

There is also evidence that stroke patients with left-side hemiplegia, or patients with cortical blindness (due to calcarine cortex damage secondary to posterior cerebral artery infarct), who paradoxically deny being blind due to anosognosia, do regain their insight after several months. Cognitive-behavioral therapy (CBT) and adherence therapy, as well as
Editorial Staff

EDITOR Jeff Bauer

SENIOR MEDICAL COPY EDITOR Eric Seger ASSISTANT EDITOR Matthew Wyles

WEB EDITOR Christina Manago

Art \& Production Staff

CREATIVE DIRECTOR Louise Koenig

ART DIRECTOR Pat Fopma

DIRECTOR, JOURNAL MANUFACTURING Michael Wendt

PRODUCTION MANAGER Donna Pituras

Publishing Staff

PUBLISHER Sharon Finch

DIRECTOR EBUSINESS DEVELOPMENT Alison Paton

SENIOR DIRECTOR OF SALES

Tim LaPella

Editor-in-Chief Emeritus

James Randolph Hillard, MD

Frontline Medical Communications

VP, SALES Mike Guire

VP, DIGITAL CONTENT \& STRATEGY

Amy Pfeiffer

PRESIDENT, CUSTOM SOLUTIONS JoAnn Wahl

CIRCULATION DIRECTOR Jared Sonners

In affiliation with Global Academy for Medical Education, LLC

PRESIDENT David J. Small, MBA

\section{FRONTLINE MLedge}

7 Century Drive, Suite 302

Parsippany, NJ 07054

Tel: (973) 206-3434

Fax: (973) 206-9378

www.frontlinemedcom.com

Subscription Inquiries: subscriptions@mdedge.com

Published through an educational partnership with

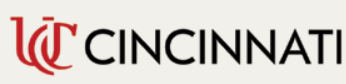


The neuroanatomy of anosognosia generally implicates right hemisphere pathology

\section{Table}

\section{Consequences of anosognosia in schizophrenia}

Refusing hospitalization for psychosis, which is associated with neurotoxicity, leading to a longer duration of untreated psychosis and significant gray and white matter loss (via neuroinflammation and oxidative stress)

Poor treatment adherence, leading to recurrent psychotic relapses, with progressive neurodegeneration and brain atrophy

Treatment resistance due to frequent psychotic relapse and structural brain changes after each psychotic episode

Increased utilization of health care, especially emergency care

High risk of suicide, especially early after onset

Increased risk of aggressive behavior and violence towards others

Functional disability (school or work)

Incarceration due to psychotic behavior during relapses

Homelessness

Early mortality due to neglect of physical health, and lack of response to physical cues of illness

psychoeducation, can help in reversing anosognosia. Bilateral electroconvulsive therapy has been reported to improve insight in schizophrenia. Transcranial magnetic stimulation over the posterior parietal cortex has been reported to restore insight in patients with visuospatial neglect due to a stroke. However, more research targeting anosognosia along with psychotic symptoms is needed. It should be noted that patients with bipolar disorder who have anosognosia during the manic phase of their illness do have insight when they switch to a depressed phase, ${ }^{9}$ which suggests that anosognosia is reversible in bipolar disorder and is phase-dependent (ie, a state, not a trait, variable).

\section{A symptom of impaired consciousness}

A large body of evidence links lesions in the right hemisphere to delusion and to anosognosia. ${ }^{24}$ Gazzaniga and Miller ${ }^{25}$ published a book chapter with the provocative title "the left hemisphere does not miss the right hemisphere." Such right-hemisphere lesions can lead to a disruption of consciousness, leading to anosognosia. Schizophrenia is a pervasive brain syndrome involving multiple brain regions and a wide range of clinical symptoms ranging across psychotic as well as negative and cognitive domains. Anosognosia can be conceptualized as a psychotic symptom (delusion), a negative symptom (self-monitoring deficit), or a cognitive failure. However, anosognosia in schizophrenia can be best understood as a symptom of impaired consciousness and self-pathology, ${ }^{26}$ where the brain fails to process and recognize one's mental function, which culminates in faulty reality testing.

Schizophrenia is a neurologic syndrome associated with numerous psychiatric manifestations, and anosognosia is one of its fundamental initial symptoms.

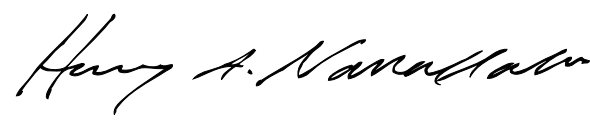

Henry A. Nasrallah, MD

Editor-in-Chief

References

1. Nasrallah HA. Impaired mental proprioception in schizophrenia. Current Psychiatry. 2012;11(8):4-5.

2. Kirsch LP, Mathys C, Papadaki C, et al. Updating beliefs beyond the here-and-now: the counter-factual self in anosognosia for hemiplegia. Brain Commun. 2021;3(2):fcab098. doi: 10.1093/braincomms/fcab098

3. Das JM, Nagvi IA. Anton syndrome. StatPearls Publishing. Updated April 10, 2021. Accessed December 13, 2021. https:/ /www.ncbi.nlm.nih.gov/ books/NBK538155/

4. Steward KA, Kretzmer T. Anosognosia in moderateto-severe traumatic brain injury: a review of prevalence, clinical correlates, and diversity considerations. Clin Neuropsychol. 2021:1-20.

5. Klarendié M, Gorišek VR, Granda G, et al. Auditory agnosia with anosognosia. Cortex. 2021;137:255-270. 


\section{Anosognosia can be conceptualized as a psychotic symptom, a negative symptom, or a cognitive failure}

\section{From the Editor}

continued from page 8

6. Bastin C, Giacomelli F, Miévis F, et al. Anosognosia in mild cognitive impairment: lack of awareness of memory difficulties characterizes prodromal Alzheimer's disease. Front Psychiatry. 202;12:631518.

7. Chen S, Song Y, Xu W, et al; Alzheimer's Disease Neuroimaging Initiative. Impaired memory awareness and loss integration in self-referential network across the progression of Alzheimer's disease spectrum. J Alzheimers Dis. 2021;83(1): 111-126.

8. Turnbull OH, Fotopoulou A, Solms M. Anosognosia as motivated unawareness: the 'defence' hypothesis revisited. Cortex. 2014;61:18-29.

9. Ibrahim SU, Kalyanasundaram VB, Ramanathan $\mathrm{SA}$, et al. Trajectory of insight on various dimensions among bipolar disorder in-patients. Ind Psychiatry J. 2020;29(2):285-292.

10. Levine DN. Unawareness of visual and sensorimotor defects: a hypothesis. Brain Cogn. 1990;13(2):233-281.

11. Pourmohammad P, Imani M, Goodarzi MA, et al Impaired complex theory of mind and low emotional self-awareness in outpatients with borderline personality disorder compared to healthy controls: a cross-sectional study. J Psychiatr Res. 2021;143: 445-450.

12. Torrey EF. Schizophrenia and the inferior parietal lobule. Schizophr Res. 2007;97(1-3):215-225.

13. Dionisio S, Mayoglou L, Cho SM, et al. Connectivity of the human insula: a cortico-cortical evoked potential (CCEP) study. Cortex. 2019;120:419-442.

14. Nord CL, Lawson RP, Dalgleish T. Disrupted dorsal mid-insula activation during interoception across psychiatric disorders. Am J Psychiatry. 2021;178(8):761-770

15. Glahn DC, Laird AR, Ellison-Wright I, et al. Metaanalysis of gray matter anomalies in schizophrenia: application of anatomic likelihood estimation and network analysis. Biol Psychiatry. 2008;64(9):774-781.
16. McEvoy JP, Freter S, Everett G, et al. Insight and the clinical outcome of schizophrenic patients. J Nerv Ment Dis. 1989;177(1):48-51.

17. Amador XF, Strauss DH, Yale SA, et al. Assessment of insight in psychosis. Am J Psychiatry. 1993;150(6): 873-879.

18. Beck AT, Baruch E, Balter JM, et al. A new instrument for measuring insight: the Beck Cognitive Insight Scale. Schizophr Res. 2004;68(2-3):319-329.

19. Kay SR, Fiszbein A, Opler LA. The positive and negative syndrome scale (PANSS) for schizophrenia. Schizophr Bull. 1987;13(2):261-276.

20. Nasrallah HA. FAST and RAPID: acronyms to prevent brain damage in stroke and psychosis Current Psychiatry. 2018;17(8):6-8.

21. Buckley PF, Wirshing DA, Bhushan P, et al. Lack of insight in schizophrenia: impact on treatment adherence. CNS Drugs. 2007;21(2):129-141.

22. Lehrer DS, Lorenz J. Anosognosia in schizophrenia: hidden in plain sight. Innov Clin Neurosci. 2014 11(5-6):101-107.

23. Emsley R, Medori R, Koen L, et al. Long-acting injectable risperidone in the treatment of subjects with recent-onset psychosis: a preliminary study. J Clin Psychopharmacol. 2008;28(2):210-213.

24. Gurin L, Blum S. Delusions and the right hemisphere a review of the case for the right hemisphere as a mediator of reality-based belief. J Neuropsychiatry Clin Neurosci. 2017;29(3):225-235.

25. Gazzaniga MS, Miller M. The left hemisphere does not miss the right hemisphere. In: Laureys S, Tonon G (eds). The Neurology of Consciousness. Cognitive Neuroscience and Neuropathology. Academic Press; 2008:261-270.

26. Cooney JW, Gazzaniga MS. Neurological disorders and the structure of human consciousness. Trends Cogn Sci. 2003;7(4):161-165. 